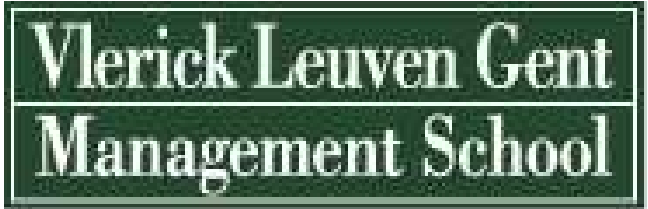

the Autovomue, Management Srhool of

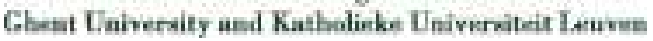

Vlerick Leuven Gent Working Paper Series 2005/31

IMPLICIT ATTITUDES TOWARD GREEN CONSUMER BEHAVIOR

DELPHINE VANTOMME

MAGGIE GEUENS

Maggie.Geuens@vlerick.be

JAN DE HOUWER

PATRICK DE PELSMACKER 


\title{
IMPLICIT ATTITUDES TOWARD GREEN CONSUMER BEHAVIOR
}

\author{
DELPHINE VANTOMME \\ Ghent University \\ MAGGIE GEUENS \\ Vlerick Leuven Gent Management School \\ JAN DE HOUWER \\ Ghent University \\ PATRICK DE PELSMACKER \\ Ghent University
}

The Special Research Fund of Ghent University funded this research.

\author{
Contact: \\ Maggie Geuens \\ Vlerick Leuven Gent Management School \\ Tel: +32092109899 \\ Fax: +32092109700 \\ Email: Maggie.Geuens@vlerick.be
}




\begin{abstract}
The purpose of this study was to examine the usefulness of implicit (automatic) attitudes to explain the weak attitude-behavior relationships often found in green consumer behavior research. Therefore, not only explicit but also implicit attitudes toward green consumer behavior were measured by means of the Implicit Association Test (IAT). Explicit measures revealed positive attitudes, while the IAT showed more positive attitudes toward the ecological than toward the traditional product (Experiment1) or no differences in these attitudes (Experiment 2 and follow-up study). When existing products were involved, implicit attitudes related to behavioral intention, even where the explicit attitude measure did not.
\end{abstract}




\section{INTRODUCTION}

Recent survey research on green consumer behavior indicates that there is strong evidence for consumer's growing environmental concern and willingness to change consumption patterns (Yam-Tang \& Chan, 1998). Alwitt and Berger (1993) reported that about seventy per cent of consumers show high levels of environmental concern. However, it seems that when it comes to purchasing and consuming products and services, buying behavior is often inconsistent with these attitudes. In fact, the market share of the majority of environmentally friendly low-involvement products amounts to less than 1\% (Roozen, 1999). This means that most consumers do not give up their traditional brands and do not convert to the environmentally friendly alternative (Grunert, 1993).

There are two classes of possible explanations for the discrepancy between environmental attitudes and actual consumer behavior. A first class relates to features of environmentally friendly products, while the second class is connected to measurement problems. The discordant character of environmentally unfriendly products may be a first reason for the low attitude-behavior consistency in green consumer behavior. On the one hand, an environmentally unfriendly product may offer important benefits to consumers, such as convenience, performance or a good price, while on the other hand environmentally friendly products respect the environment, but may show a lower quality or higher prices (Alwitt \& Berger, 1993). Further, even if people express positive attitudes toward environmentally friendly products, this may not be translated in actual purchase behavior because there is not in every product category a green alternative available (Yam-Tang \& Chan, 1998). A last reason is that in case of environmentally friendly products, the ethical criterion (being environmentally harmless) is just not taken into account. Price, quality ,convenience and brand familiarity are still the most important decision factors (Roberts, 1996; Tallontire et al., 2001).

With respect to measurement problems in research on green consumer behavior, several authors (La Trobe, 2000; Roozen \& De Pelsmacker, 1998) agree that people are motivated to hide their real attitudes and/or purchase patterns and falsely claim that they actually buy environmentally friendly products, in order to impress the researcher or to hide personally or socially undesirable behavior. Another source of bias is 'leading 
questioning'. Questions like "I would rather use products with recyclable packages than with no recyclable packages" have been proven to exert a directing influence on consumers (Schwepker \& Cornell, 1991). Further, in self-report attitude measures respondents are forced to express an opinion. Even when people are unfamiliar with the attitude-object, they will still answer the question in order not to seem ignorant. In such cases, respondents think and look for information in order to form a meaningful evaluation, which often results in 'artificial' evaluations and opinions that do not reflect the real (spontaneous) evaluation (Kardes et al. 1993). Finally, self-report measures assume that respondents are aware of (i.e. have access to) their attitudes. However, substantial research on social cognition suggests that a large portion of our daily activities is the result of cognitive processes that occur outside conscious awareness and control (Greenwald and Banaji, 1995; Bargh, 2002).Traditional self-report measures are not well suited to capture these implicit processes.

The latter point is related to the recent distinction between explicit attitudes on the one hand and implicit or automatic attitudes on the other hand (Fazio, 1990; Wilson, Lindsey, \& Schooler, 2000). Explicit attitudes are attitudes that operate in a conscious mode and are typically measured by self-report tasks (surveys). Implicit attitudes are "introspectively unidentified (or inaccurately identified) traces of past experience that mediate favorable or unfavorable feeling, thought, or action toward social objects" (Greenwald \& Banaji, 1995, p. 8). The distinction between implicit and explicit attitudes is consistent with the view of dual-processing models that are commonly used in consumer behavior research such as the ELM (Petty \& Cacioppo, 1986) and MODEmodel (Fazio, 1990). Dual processing models distinguish two types of attitude-tobehavior processes: deliberative or cognitive processing and spontaneous or automatic processing. According to this view, implicit attitudes are the result of spontaneous processing and assumed to guide spontaneous (automatic) behavior, whereas explicit attitudes are the result of deliberative processing and should be the basis for intentional actions (Wilson et al., 2000). Whether people engage in spontaneous versus deliberative processing depends on the motivation and opportunity of the individual to process the information. However, it is not hard to imagine that consumers do not always have the opportunity or the motivation to process an advertisements' content or to elaborate 
thoroughly on which brand to choose. Consumers in the supermarket, for instance, often pick products out of the shelves without deliberating on the personal costs and benefits attached to buying these products. Moreover, more and more researchers recognize the fundamental role that affect and unconscious motives may play in consumer decisions (Pham, 1998; Pham, Cohen, Prajecus, \& Hughes, 2001; Shiv \& Fedorkin, 1999). Further, earlier empirical findings in consumer research can be reinterpreted as implicit attitude effects (Greenwald \& Banaji, 1995). The mere exposure effect, for instance, explains that the mere exposure to an ad or product may lead to a greater liking of that ad or product, even without an explicit recognition of the ad or product (Janiszewski, 1990, 2001; Shapiro, 1999). Another example can be found in halo-effect research where physically attractive models are shown to be the objectively irrelevant attributes that influence evaluations of advertisements on other dimensions, such as quality (Baker \& Churchill, 1977; Greenwald \& Banaji, 1995; Patzer, 1985). Finally, Bargh (2002) suggests that "the realm of consumer research would be the ideal playing field on which to establish whether the new models of automatic evaluation processes do, indeed, apply in the real world...".

The arguments presented above suggest that the inconsistency between green consumer behavior and self-reported attitudes could be due to problems with self-report measures. Recently, researchers have developed a number of alternative attitude measures that do not rely on self-reports. These measures are assumed to register implicit attitudes and to be less sensitive to social desirability effects. If the weak attitudebehavior consistency in the context of green consumer behavior is indeed due to measurement problems, one would thus expect that the results of these alternative attitude measures should be more consistent with actual green consumer behavior. That is, contrary to explicit measures, implicit measures could reveal that consumers have a more negative implicit attitude toward green products than toward traditional products. We tested this prediction in two experiments in which we used the Implicit Association Test (IAT) to measure implicit attitudes toward fictitious (Experiment 1) and real green products (Experiment 2). Before we describe these experiments, we will describe the IAT, present a brief overview of initial experiments using the IAT in consumer behavior research, and formulate our hypotheses. 


\section{IMPLICIT ATTITUDE MEASUREMENT}

Implicit attitudes can be measured by indirect measures that use reaction time as an indicator of automatically activated attitudes. Examples of such measures are the Implicit Association Test (Greenwald et al., 1998), the (Extrinsic) Affective Simon Task (De Houwer, 2003; De Houwer, Crombez, Baeyens, \& Hermans, 2001) and the Go/Nogo Association Task (Nosek \& Banaji, 2001). The assumption behind those indirect measures is that in memory, an attitude is stored as an association between the representation of the attitude object and the representation of positive and negative valence (e.g. Fazio, 1986). Therefore, respondents will perform instructions that prime the same (re)action toward concepts that are associated in mind faster than instructions that demand a similar action toward concepts that are not or less associated in mind. Because respondents cannot control the influence of attitudes on their response latencies, the advantage of using latency judgments is that they circumvent reliance on the willingness or ability of respondents to express their opinions.

\section{The Implicit Association Test}

One method of examining implicit attitudes that has received a lot of attention over the past years is the Implicit Association Test (IAT, Dasgupta, McGhee, Greenwald, \& Banaji, 2000; Greenwald, McGhee, \& Schwartz, 1998). The IAT is a computerized response latency task that measures the strengths of associations between concepts. Respondents are asked to categorize stimuli that represent two pairs of contrasted concepts (two target concepts and two attribute concepts) as fast and accurately as possible. More specifically, during the IAT, respondents press a left or a right computer key based on the category to which the presented stimulus belongs (e.g., flower name, insect name, pleasant or unpleasant word). In the first task, respondents are instructed to press the left key when pleasant words and words referring to the first target concept appear on the screen and to press the right key when unpleasant words or words referring to the second target concept (e.g., insects) pop up. In the second task, instructions are reversed (e.g., press left for insects and positive words; press right for flowers and negative words). If the target concepts are differentially associated with the attribute 
dimensions, respondents should find one of the two combined tasks easier. The difference in response latency is thus an indicator of the implicit attitudinal difference between the target categories. In many experiments, superior performance was found for the evaluative compatible combinations (flowers + pleasant words) as compared to the incompatible combinations (insects + pleasant words). Thus far, substantial evidence exists for the IAT's convergent and discriminant validity (Greenwald \& Nosek, 2001). Further, the IAT has shown to be a very useful tool for research on different topics such as racial attitudes (Dasgupta \& Greenwald, 2001), stigmatized behavior such as smoking (Swanson et al., 2001), and gender stereotypes (Rudman, Greenwald, \& McGhee, 2001).

\section{IAT in consumer research}

Only a few studies have used the IAT to measure consumer attitudes. Maison et al. $(2001,2004)$ examined implicit attitudes toward different types of products (juices and sodas; low and high calorie products) and brands (brands of yogurt, fast food restaurants and cola). The results showed positive correlations between implicit attitudes as measured by the IAT and both explicit attitudes and behavior (self-reported and observed). In general, frequent users of a particular product or brand had IAT reaction times indicating a more favorable implicit attitude toward that brand than light users. Further, the meta-analysis of three combined experiments indicated that including IAT measures as predictors increased the prediction of behavior relative to explicit attitude measures alone. A study by Wänke, Plessner, and Friese (2002) investigated attitudes toward food products of well-established and no-name brands. For the respondents with a difference between implicit and explicit attitudes, the results revealed that, at the end of the experiment, 90\% chose the brand congruent with their explicit attitude (and incongruent with their implicit attitude) when there was no time restriction for making the choice. For respondents with similar implicit and explicit attitudes, $82 \%$ chose the brand congruent with their attitudes. When time pressure was imposed, only 38\% of the respondents with different implicit and explicit attitudes chose the brand consistent with their explicit attitudes, while $62 \%$ chose the brand congruent with their implicit attitudes. For respondents with similar attitudes, again $83 \%$ preferred the brand congruent with their attitudes. This means that the data support the assumption that when implicit and 
explicit attitudes differ, spontaneous behavior is more consistent with implicit than with explicit attitudes, while the opposite is true for controlled behavior. In consumer research, it has until now not yet been examined whether implicit attitudes are more strongly related to behavior as compared to explicit attitudes in situations where consistently weak (explicit) attitude-behavior relationships are found.

\section{PRESENT RESEARCH}

As we stated earlier, the purpose of our study was to explore the usefulness of the IAT for determining consumers' attitudes toward environmentally friendly products. We chose (environmentally friendly) cleaning products as attitude objects. Implicit attitudes toward cleaning products are likely to have an important impact on consumer behavior because cleaning products are low-involvement products that do not involve long effortful considerations on which brand to choose. Moreover, for most respondents, explicit and implicit attitudes toward green products are expected to differ, because these products are subject to ethical concerns and social norms. The IAT may thus reveal another view on the evaluation of green products than self-report measures because the IAT is assumed to register implicit rather than explicit attitudes and is assumed to be less susceptible to deception and self-presentational strategies (Dovidio \& Fazio, 1992; Greenwald \& Banaji, 1998; Dasgupta et al., 2000).

\section{EXPERIMENT 1}

The purpose of Experiment 1 was to measure implicit and explicit attitudes toward two fictitious brands of cleaning products. We also registered purchase intentions with respect to those brands and four real all-purpose cleaners.

\section{Method}

Participants. Sixty undergraduate students (26 women, 34 men) of the Department of Applied Economics at Ghent University (Belgium) participated in the 
experiment in exchange for a movie ticket. All respondents were between 17 and 27 years old $\left(\mathrm{M}_{\mathrm{age}}=21.53, \mathrm{SD}=1.42\right)$.

Overview. The experiment consisted of four phases: (1) a learning phase, (2) an IAT, (3) an explicit measure of attitudes toward two fictitious brands, and (4) two behavioral intention measures: one with the fictitious and one with real products. The IAT precedes the explicit measures because this avoids that the explicit measure might influence the results of the IAT (see Bosson, Swann, \& Pennebaker, 2000; Fazio \& Olson, 2003). The computer tasks (learning phase and IAT) were completed on PC-type desktop computers with AZERTY keyboards, using Inquisit laboratory software (2002). The entire study was conducted individually and took about 40 minutes.

Learning phase. Using a learning phase at the beginning of the experiment offers researchers the possibility to teach respondents new attitudes. An important advantage of this approach is that idiosyncratic differences in previous experience or perception cannot interfere with attitude measurement toward these objects. Consequently, it allows the researcher to manipulate only those features that are of interest for the study, without the features being confounded with influences of familiarity or previous experiences. During the learning phase, the new attitude-object was systematically shown together with certain attributes, which resulted - over time - in an association between the attitudeobject and the attributes (see De Houwer, Thomas, \& Baeyens, 2001). During the learning phase of the current experiment, two fictitious brand names for cleaning products ( 2 non-words, Matu and Giko) were paired together with their specific characteristics described in words (for the green product: minimal packaging, recyclable, green label and a price premium; for the traditional product: attractive packaging, nonrecyclable, extensive media-support and standard price). Respondents were told that both brands were of good quality. They were instructed to memorize the brand names and their accompanying characteristics. This was repeated ten times for each brand. Each trial in the learning phase consisted of the following sequence of events: the brand name for $2500 \mathrm{~ms}$, a black screen for $1000 \mathrm{~ms}$ and the brand characteristics for $5000 \mathrm{~ms}$. The intertrial interval (ITI) was $4000 \mathrm{~ms}$. After five pairings of both names, a memory test was presented. During the memory test, respondents were asked to indicate for each characteristic to which brand name it belonged. Then the names and the characteristics 
appeared again five times, followed by an identical memory test. The pairing of the brand name and the characteristics (Matu is environmentally friendly or Giko is environmentally friendly) and the order of learning the brands (Matu on the first five trials or Giko on the first five trials) were counterbalanced.

IAT. After the learning phase, the experimenter initiated a second computer program that was used to control the IAT phase. The IAT was designed to measure implicit attitudes toward the two fictitious brands. The target stimuli were the two fictitious brand names GIKO and MATU. Two target stimuli are appropriate because Nosek, Greenwald, and Banaji (2003) demonstrated that IAT effects are robust even with few stimuli. Moreover, Mcfarland and Crouch (2002) concluded that IAT's with just two exemplars in each category - as compared to IATs with more exemplars in each category- are less confounded with a general cognitive ability level of how quickly one can process the compatible versus the incompatible block in the test.

As attribute stimuli, we used positive (love, peace, funny, honest, beautiful, happiness) and negative (death, cancer, hatred, ugly, false, imprudent) words. Letter case (upper or lower case) for the attribute stimuli and letter case and color (white, yellow and pink) for the target concept stimuli were varied in order to reduce the possibility that participants responded on the basis of a simple visual feature of the names. Stimuli were presented in the center of the computer screen and the respondents' task was to assign each stimulus to one of two categories. The interval between pressing the correct response key and presentation of the next stimulus was $150 \mathrm{~ms}$.

The IAT consisted of seven classification tasks. During the first task, only positive and negative words were presented. Positive words were always assigned to the right key (M) and negative words to the left key (Q). Each positive and negative word was presented 12 times. The second task consisted of categorizing the brand names: GIKO was assigned to the left key, MATU to the right key. Each brand name appeared 12 times on the screen. Task three and four (practice and data collection trials) combined both categorization tasks: GIKO and the negative words were assigned to the left key, MATU and the positive words to the right key. Each stimulus was presented 6 times on the practice trials and 12 times on the data collection trials. The fifth task consisted of classifying the brand names once again, but now MATU was assigned to the left key and 
GIKO to the right key (=the reverse of task 2). Again, MATU and GIKO appeared 12 times on the screen. During block six and seven (practice and data collection trials) the reversed categorization task was combined with task 1. Consequently, MATU and the negative words were assigned to the left key and GIKO and the positive words to the right key. During the practice trials, each stimulus was presented 6 times, while this amounted to 12 times during the data collection trials. Before and during each phase, the name of the target and/or attribute concept (MATU, GIKO, POSITIVE and/or NEGATIVE) that was assigned to the left key was printed in the top left corner of the screen, whereas the name of the target and/ or attribute concept that was assigned to the right key was written in the top right corner of the screen. Participants were asked to respond as quickly but also as accurately as possible. Summary feedback was given in the form of mean response latency in seconds and percentage correct following each block. All blocks were respondent-initiated. In case of an incorrect response, a red cross appeared on the screen for $400 \mathrm{~ms}$. The IAT-effect was computed by subtracting the mean response latency for performing the 'ecological product combined with positive words'task (Combination 1) from the 'ecological product combined with negative words'-task (Combination 2). Thus, positive difference scores reflected more positive implicit attitudes toward the green product as compared to the traditional product.

Explicit measures. After the computer tasks, respondents completed paper-andpencil measures of attitudes and behavioral intentions. The explicit measure consisted of two parts: (1) explicit measure of attitudes and behavioral intentions toward the two fictitious brands, and (2) behavioral intention measure toward real cleaning products.

Attitudes toward the two fictitious brands were measured by means of a six-item seven-point semantic differential scale (Geuens \& De Pelsmacker, 2002: pleasant, unsatisfactory, nice, worthless, unattractive and good) (Cronbach's Alpha $=.88$ which is sufficiently high to allow to calculate an average across the items); Behavioral intention was measured by asking the respondents which of the two fictitious brands they would buy.

A second measure of behavioral intention presented the respondents with the pictures and prices of four well-known brands of all-purpose cleaners: one ecological brand, two A-brands and one private label. The A-brands were about $10 \%$ cheaper than 
the green brand; the private label was $34 \%$ cheaper. Respondents were asked to indicate which product they would buy. Price-related information was included to make the experiment more realistic as a price premium is an inherent feature of most ecological products.

As described above, the explicit attitude measure did not include leading questions and both the attitude and behavioral intention measure related to concrete cleaning products. For half of the respondents the explicit measures started with the behavior and the behavioral intention questions, for the other half the first questions were related to attitudes.

\section{Results}

Explicit attitudes. Attitudes toward the ecological $\left(M_{\text {ecological }}=4.80\right)$ and traditional cleaning product $\left(M_{\text {traditional }}=4.72\right)$ did not differ significantly, $t(60)<1$. Both scores were significantly more positive than the scales mid-point, showing that the participants had a positive attitude toward both products. In order to be able to compare explicit and implicit attitude measures in further analyses, we related both explicit measures in a difference score. The difference score was calculated by subtracting the ratings for the traditional product from ratings for the green product, resulting in a relative explicit attitude measure $\left(M_{\text {difference }}=.08\right)$. Positive values on the difference score indicate a favorable rating of the green product, negative scores a favorable rating of traditional products.

IAT measure. In accordance with Greenwald et al. (1998) reaction times shorter than $300 \mathrm{~ms}$ and larger than $3000 \mathrm{~ms}$ were recoded into $300 \mathrm{~ms}$ and $3000 \mathrm{~ms}$ respectively. Also, the first two trials of each block were dropped because of their typically longer latencies, as were reaction times and trials with an incorrect response. Next, reaction times were log-transformed. However, for reasons of clarity, response latencies in terms of ms will be reported in further analyses (See Greenwald et al., 1998). The average error rate was $2.75 \%$ (range $0 \%-12.5 \%$ ).

Results showed that respondents had on average significantly shorter reaction times when the green product was paired with positive words $(M=832 \mathrm{~ms})$ than when the traditional product was paired with positive words $(M=883 \mathrm{~ms}), t(57)=2.38, p=.02$. 
This indicates that respondents in general had more positive implicit attitudes toward the green than toward the traditional product.

Relationship between explicit attitudes, implicit attitudes, and behavioral intention. Table 1 shows implicit and explicit attitudes toward the fictitious ecological products (relative to fictitious traditional products) as a function of behavioral intention toward the real well-known brands of all-purpose cleaners. The IAT-effect, but not the explicit difference score, differentiated between respondents intending to buy the real ecological all-purpose cleaner and those intending to buy the real traditional all-purpose cleaner. With respect to the fictitious brands (i.e. MATU and GIKO, Table 2) ${ }^{1}$, the explicit difference score significantly differentiated between respondents preferring the ecological brand and those preferring the traditional brand. The IAT was related to behavioral intention toward the fictitious brands in the expected direction: respondents willing to buy the ecological brand showed more positive implicit attitudes toward the green brand as compared to those willing to buy the traditional brand. However, the difference was not significant. Finally, the IAT was not correlated with the explicit difference score $(r=.19, p=.15)$.

Insert Table 1 and Table 2 about here

\section{Discussion}

The results of Experiment 1 confirm findings of previous research as the explicit attitude measure showed strong positive attitudes toward the green product. Because these positive explicit attitudes might be distorted by typical drawbacks of explicit measurement, we hypothesized that an implicit attitude measurement might give a less optimistic view on consumers' green attitudes. Surprisingly, the reverse was true. Whereas explicit attitudes toward the green and traditional product did not differ, the implicit attitude toward the green product was significantly more positive than the implicit attitude toward the traditional product. This means that we did not find support for the hypothesis that implicit attitudes are less positive toward green products as compared to traditional products. 
Finding positive implicit attitudes does, however, not indicate that implicit attitudes play no role in the purchase of green products. This first experiment showed that interindividual differences in implicit attitudes as measured by the IAT were significantly related to interindividual differences in purchase intentions of real green brands. Those participants who said that they would purchase an existing ecological all-purpose cleaner had a more positive implicit attitude toward the environmentally friendly brand (as compared to the traditional brand) than participants who said that they would buy the traditional product. What is even more interesting is that implicit attitudes were related to purchase intentions when explicit attitudes were not. That is, purchase intentions with regard to real products were related to implicit but not explicit attitudes toward the fictitious ecological and traditional brands. Further, the IAT was related in the expected direction to purchase intentions toward the fictitious brands, although not significantly. These findings strongly suggest that implicit attitudes and behavioral intention are interrelated and that implicit attitudes may provide an unique insight in green consumer behavior.

However, the use of fictitious products in the current experiment might have led to an underestimation of the (automatic) processes operative when evaluating and buying real cleaning products (at the time of purchase). That is, when using fictitious brands in the attitude measure, "traces of past experience" with the concrete product might not moderate its evaluation. Although past experience with green products in general is likely to have influenced the evaluation of the fictitious brands, we believe that including both attitude and behavioral intention measures toward real, concrete products might evoke to a larger extent processes active at the time of purchase. Evoking processes active at the time of purchase might be important because the data in Experiment 1 suggest that the IAT has registered a more general affective reaction toward ecological cleaning products in general rather than a rational weighting of the characteristics of the fictitious brands. That is, implicit attitudes toward the fictitious products related to purchase intention toward the real, but not the fictitious products. We will elaborate on this conclusion in the general discussion.

Further, on the basis of the current experiment, we cannot conclude that only implicit attitudes are related to purchase intention toward real environmentally friendly 
products. It is, for instance, possible that explicit attitudes toward the fictitious brands are not associated with behavioral intention toward real products because of a mismatch in the level of specificity of both measures. After all, according to Ajzen (1991) and Ajzen and Fishbein (1977), attitude and behavior measures should match in their levels of specificity in order to find a relationship. This means, for instance, that attitudes that are measured toward environmentally friendly consumer behavior in general will not relate to behavior with respect to specific products or vice versa.

In order to address the remarks emerging from Experiment 1, Experiment 2 included attitude measures toward real cleaning products.

\section{EXPERIMENT 2}

The purpose of Experiment 2 was to measure implicit and explicit attitudes toward two assortments of real cleaning products. Further, purchase intentions with respect to the assortment and four real all-purpose cleaners were registered.

\section{Method}

Participants. The respondents were 72 undergraduate students (35 women, 37 men) recruited from several university departments. All participants were between 18 and 27 years old $\left(M_{\mathrm{age}}=22.03, \mathrm{SD}=2.13\right)$.

Overview. The experiment consisted of five phases: (1) inspection of the products displayed on the table, (2) a learning phase, (3) an IAT, (4) an explicit measure of attitudes toward the two assortments (displayed on the table), and (5) two behavioral intention measures. The experiment was conducted individually and took about 25 minutes.

Exposure. Upon arrival in the laboratory, respondents were asked to have a thorough look at the two product assortments displayed on the table. The first assortment was labeled 'Assortment I' and contained four environmentally friendly cleaning products sold in Belgium: Two products of the brand 'Ecover' (bathroom-cleaner and allpurpose-cleaner) and two products of the brand 'Froggy' (abrasive cream and toiletcleaner). The other assortment (Assortment II) included the same four types of cleaning 
products, but now of the (environmentally harmful) Cif and Bref brands. The presence of the products was expected to evoke conscious (and unconscious) representations of previous experiences with this type of products, processes that might direct evaluation. The label of the assortments was counterbalanced across participants and respondents were randomly assigned to the two treatment groups.

Learning phase. The purpose of the learning phase was to be certain that respondents associated each product with the correct assortment. During the learning phase, both assortment labels were presented together with each of its four products on one trial. Respondents were instructed to memorize the assortment labels and their accompanying products. Each trial in the learning phase consisted of three sub events: the assortment label for $2500 \mathrm{~ms}$, a black screen for $1000 \mathrm{~ms}$ and a picture of a cleaning product for $5000 \mathrm{~ms}$. The intertrial interval was $4000 \mathrm{~ms}$. In the memory test following the learning phase, respondents had to indicate to which assortment the product presented on the computer screen belonged by pressing the appropriate key. When the memory test was error free (which was the case for all respondents), the IAT was instigated.

IAT. The IAT measured implicit attitudes toward the two assortments displayed on the table. The target stimuli consisted of pictures of the products belonging to the two assortments. All pictures had the same format, size and brightness. Pictures were used because earlier research demonstrated that pictures could be evaluated automatically and even faster than words (De Houwer \& Hermans, 1994; Giner-Sorolla, Garia \& Bargh, 1999; Hermans, De Houwer \& Eelen, 1994). The attribute stimuli were pictures (and not words) of positive and negative valence that were taken from the International Affective Picture System (1999) ${ }^{1}$. The target category labels were 'Assortment I' and 'Assortment II, the attribute category labels were 'positive' and 'negative'. Participants were instructed to assign the pictures to the corresponding categories as fast and accurately as possible. In all other respects, the IAT was identical to the one in previous experiments. After the computer-aided tasks, respondents filled in a paper-and-pencil questionnaire.

Explicit measures. The explicit attitude measures were six-item seven-point scales measuring attitudes toward the two assortments as a whole (and not toward the individual products belonging to the assortments). The first behavioral intention measure determined intentions toward the two assortments, while the second measured intention toward four 
different all-purpose cleaners (from the brands Ecover, Ajax, Mister Proper and a private label) represented by a picture and price indication. The latter measurement instrument differed from the one in Experiment 1 in that the environmentally friendly product was no longer the most expensive option (one A-brand had a higher and one A-brand had a lower price as compared to the ecological brand). This meant that price could not be the most important reason for not intending to buy the ecological product.

\section{Results}

Explicit attitudes. In line with previous findings, the explicit measures showed attitudes toward the ecological assortment that were significantly more positive than the scales' mid-point $(p<.001)$ and that were of equal level as the attitudes toward the traditional assortment $\left(M_{\text {ecological }}=4.56, M_{\text {traditional }}=4.71, t(71)<1, p=0.434\right)$. Again, we calculated a difference score to enable a comparison between explicit and implicit measures in further analysis. The difference score was obtained by subtracting the ratings for the traditional assortment from the ratings for the green assortment, which resulted in a relative explicit attitude measure with a mean score of -0.16 .

Implicit attitudes. The IAT effect was calculated in the same way as in the previous experiment. One respondent had to be excluded from the analyses because of an average error rate higher than $30 \%$ in the incompatible block (see Maison et al., 2001). The high error rate suggested that the respondent either misunderstood the task or did not carry it out seriously. The average error rate of the other respondents was $2.45 \%$ (range 0\%-22.92\%). The implicit attitude measure revealed a non-significant negative IATeffect ( $M=-4 \mathrm{~ms}$ ), indicating that the response latencies did not differ when the ecological assortment was combined with positive words ( $M=948 \mathrm{~ms})$ as compared to when the traditional assortment was combined with positive words ( $M=944 \mathrm{~ms}$ ), $t(69)<1$.

Relationship between explicit and implicit attitudes and behavioral intention. The results of an independent samples $t$-test showed that both the IAT and the explicit difference score were related to the behavioral intention measures. Respondents who chose the ecological products (for both the assortments and the real products) demonstrated significantly more positive scores on the IAT and the explicit difference 
measure as compared to respondents choosing the traditional products (see Tables 3 and 4). Conversely, this experiment does suggest that both spontaneous and deliberative processes are related to purchase intentions for environmentally friendly products. Finally, a positive correlation was found between the IAT and the explicit difference score $(\mathrm{r}=0.33, p<0.01)$.

Insert Table 3 and Table 4 about here

\section{Discussion}

The results of the IAT showed similar implicit attitudes toward the ecological and traditional assortment. Further, interindividual differences in implicit attitudes were significantly related to interindividual differences in purchase intentions for both intention measures. Respondents intending to buy ecological products, showed significantly more positive implicit attitudes toward the ecological products as compared to respondents intending to buy traditional products. Moreover, the same differentiation was found for the explicit attitude measures, a finding that indicates that both implicit and explicit processes guide the purchase of cleaning products. Because IAT labels rather than the individual stimuli representing the labels are shown to be important in determining the IAT-effect (De Houwer, 2001; Govan and Williams, 2004), we conducted a follow-up study $(\mathrm{N}=31)$ using the IAT labels 'traditional assortment' versus 'ecological assortment'. The previous results were replicated suggesting that both IATs measured implicit attitudes toward ecological products relative to traditional products and thus, that label choice was not likely to bias the results.

\section{GENERAL DISCUSSION}

The purpose of this research was to examine the usefulness of implicit attitude measures with respect to environmentally friendly products. In line with previous research, the two experiments and the follow-up study revealed equally positive explicit attitudes toward environmentally friendly low-involvement products. In Experiment 1, implicit attitudes toward the ecological brand were significantly more positive as 
compared to those toward the traditional brand, whereas in Experiment 2 and the followup study implicit attitudes toward the ecological assortment did not differ from those toward the traditional assortment. These findings are contrary to expectations as they suggest that implicit attitudes toward environmentally friendly products are not as negative as could be expected on the basis of previous research and actual consumer behavior (Kardes et al., 1993; La Trobe, 2000; Roozen \& De Pelsmacker, 1998). This implies that we did not find support for the hypothesis that positive explicit attitudes result from drawbacks of explicit measurement such as social desirability bias or 'rationalization' of introspectively inaccessible attitudes. By exclusion, it thus seems that the weak attitude-behavior relationships often found in green consumer behavior research can be ascribed to intrinsic features of environmentally friendly products such as their discordant character or the fact that the ethical aspect is just not taken into account rather than to measurement problems of explicit attitude measures.

However, the conclusion that implicit attitudes toward environmentally friendly products are equally or even more positive does not imply that implicit attitudes are unrelated to purchase intention. On the contrary, when real products were involved, implicit attitudes correlated significantly with purchase intention, even when the explicit attitude measures did not. For the three experiments, we found that respondents intending to buy real ecological product(s) held more positive implicit attitudes toward the ecological product(s) than the traditional product(s) and vice versa. This conclusion cannot be drawn for explicit attitude measurement, as in Experiment 1 explicit attitudes were only related to purchase intention toward the fictitious brands and not to real products. This means that purchase intention toward real products correlates more consistently with implicit than explicit attitudes toward fictitious brands.

In Experiment 2 and the follow-up study, however, explicit attitudes toward assortments of real products was related to behavioral intention toward real products. This suggests that when attitude and behavior measures had the same level of specificity (both measures related to real products), a relationship between the two explicit measures was found. These findings confirm previous research (Ajzen, 1991; Ajzen \& Fishbein, 1977) suggesting that explicit attitude and behavioral intention measures should match on level of specificity in order to find a relation between both. Further, finding a relationship 
between the explicit attitude measure and the purchase intention measure when both measures relate to real products (in Experiment 2 and the follow-up study), but not when the explicit attitude measure relate to fictitious brands and the purchase intention measure to real products (Experiment 1), suggests that the evaluation of fictitious brands differs from the evaluation of concrete products. Because explicit attitudes are by definition a rational weighting of explicit product characteristics (Ajzen \& Fishbein, 1977), it is likely that in case of fictitious brands, evaluation is the result of rationally weighting characteristics such as 'green label', 'recyclable', 'minimal packaging', etc listed (but not visualized) at the beginning of the experiment. However, when real products are involved, it can be presumed that other (more) product characteristics are included in the weighting, such as previous experience with the concrete product(s), concrete price indications, a less (more) attractive packaging, the smell the product gives out, familiarity with the product (e.g. due to commercials on television), etc.

From this perspective, it is interesting to note that our data suggest that implicit attitude-behavioral intention relationships will be found for real products, even when the level of specificity of both measures differs. This could be due to the fact that the IAT captures an overall spontaneous affective reaction toward the "ecological cleaning products" rather than a rational weighting of explicit product characteristics (Rudman \& Heppen, 2003).

In sum, the current paper shows positive or neutral implicit attitudes toward environmentally friendly products (as compared to traditional products) that do relate to environmentally friendly consumer behavior, even more consistently than explicit attitudes when real products are involved. This indicates that implicit attitudes and the IAT may be valuable for green consumer research. However, questions on the predictive validity of implicit attitudes for variations in green consumer behavior beyond those explained by explicit measures remain unanswered and lay beyond the scope of this article. Therefore, future research should concentrate on the conditions under which implicit versus explicit attitudes are more/less related to behavioral intentions or when one type and not the other (and visa versa) is related to intentions. Related to the latter questions is that more insight is needed on the malleability of implicit attitudes and their sensitivity to social norms. Are implicit attitudes indeed expressed without intention or 
control $^{3}$ (Dasgupta et al. 2003) and therefore less sensitive to social norms? Or, on the contrary, are implicit attitudes- as Wittenbrink et al. (2001) and Blair (2001) indicatecontext dependent, malleable and thus just like explicit measures subject to social desirability bias? Further, it remains unclear whether the IAT measures individual attitudes rather than cultural associations. Banaji (2001) and Lowery (2001), for instance, have emphasised the difficulty of distinguishing cultural associations from personal ones because attitudes are likely to stem from learning experiences in a particular culture. In racial prejudice research for instance, it is argued that the strong associations between Blacks and negativity for both Black and White respondents can (at least) partly be ascribed to the fact that Blacks have been historically portrayed in a negative manner by American society (Nosek, Banaji and Greenwald, 2002; Fazio and Olson, 2003). In this respect, the fairly positive implicit attitudes toward green products could be the result of culturally imposed associations between green products and positivity.

The current study could be extended to other product categories, for instance a hedonic instead of an utilitarian product. As the purchase of hedonic products is especially driven by affective motives, implicit attitudes may reach rich insights in the attitude-behavior relationship concerning those products. Finally, it remains valuable to look for areas of consumer behavior for which implicit measurement may be more accurate since it is suggested that explicit measurements are influenced by social desirability biases or other distortions. Examples of such areas are attitudes toward controversial ads, containing for example sex, nudity, or homosexual elements (Maison et al., 2004). Similar, the IAT could be used to better understand (implicit) attitudes toward risky behaviors such as drinking and driving, drug abuse, etc.

Another range of applications for the IAT is the study of brand attitudes and the role of brands in consumer decisions. Because brand attitudes often operate through brand images that are not necessarily conscious, explicit measurement may not be sufficient. Finally, the IAT has potential in new product development and in advancing research concerning brand relationships (Fournier, 1998), brand community (McAlexander, Schouten, \& Koenig, 2002) and consumer identity. 


\section{FOOTNOTES}

1. The differential distribution of respondents over the two types of products in Table 1 and Table 2 can be ascribed to the fact that the results in Table 1 reflect respondents' choice out of four alternatives (one environmentally friendly all-purpose cleaner and three traditional all-purpose cleaners), whereas the results in Table 2 reflect respondents' choice between on the one hand an environmentally friendly cleaning product and on the other hand a traditional cleaning product.

2. The IAPS numbers of the picture used in Experiment 3 are: 1710, 2340, 2540, 4641, 8380, 8461 (positive pictures) and 3100, 3350, 6010, 6313, 9040, 9433 (negative pictures).

3. According to Dasgupta et al. (2003), for the IAT, the emphasis is on controllability and not on 'automaticity' : "IAT responses are considered automatic because they are expressed without intention or control, although perceivers may become aware of the attitude under scrutiny during the task" 


\section{REFERENCES}

Ajzen, I. (1991). The theory of planned behavior. Organizational Behavior and Human Decision Processes, 50, 179-211.

Ajzen, I., \& Fishbein, M. (1977). Attitude-behavior relations: A theoretical analysis and review of empirical research. Psychological Bulletin, 84, 888-918.

Alwitt, L. F., \& Berger, I. E. (1993). Understanding the link between environmental attitudes and consumer product usage: Measuring the moderating role of attitude strength. In L. McAliste, \& M. L. Rothschild (Eds.), Advances in Consumer Research （Vol. 20, pp. 189-194). Provo, UT: Association for Consumer Research.

Baker, M. J., \& Churchill Jr., G. A. (1977). The impact of physically attractive models on advertising evaluations. Journal of Marketing Research, 14, 538-555.

Banaji, M. R. (2001). Implicit attitudes can be measured. In H. L. Roediger \& J. S. Nairne (Eds.), The nature of remembering: essays in honor of Robert G. Crowder (pp. 117-150). Washington, DC: Am. Psychol. Assoc.

Bargh, J. A. (2002). Losing consciousness: Automatic influences on consumer judgment, behavior and motivation. Journal of Consumer Research, 29, 281-285.

Blair, I.V., Ma, J.E., \& Lenton, A.P. (2001). Imagining stereotypes away: The moderation of implicit stereotypes through mental imagery. Journal of Personality and Social Psychology, 81, 828-841.

Bosson, J.K., Swann, W.B., \& Pennebaker, J.W. (2000). Stalking the perfect measure of implicit self-esteem: The blind men and the elephant revisited? Journal of Personality and Social Psychology, 79, 631-643.

Dasgupta, N., \& Greenwald, A. G. (2001). Exposure to admired group members reduces automatic intergroup bias. Journal of Personality and Social Psychology, 81, 800-814. 
Dasgupta, N., Greenwald, A. G., \& Banaji, M. R. (2003). The first ontological challenge to the IAT: Attitude or mere familiarity? Psychological Inquiry, 14, 238-243.

Dasgupta, N., McGhee, D.E., Greenwald, A.G., Banaji, M.R. (2000). Automatic preference for White Americans: eliminating the familiarity explanation. Journal of Experimental Social Psychology, 36, 316-328.

De Houwer, J. (2001). A structural and process analysis of the Implicit Association Test. Journal of Experimental Social Psychology, 37, 443-451.

De Houwer, J. (2003). The Extrinsic Affective Simon Task. Experimental Psychology, $50,77-85$.

De Houwer, J., Crombez, G., Baeyens, F. \& Hermans, D. (2001). On the generality of the affective simon effect. Cognition and Emotion, 15, 189-206.

De Houwer, J., \& Hermans, D. (1994). Differences in the affective processing of words and pictures. Cognition and Emotion, 8, 1-20.

De Houwer, J., Thomas, S., \& Baeyens, F. (2001). Associative learning of likes and dislikes: A review of 25 years of research on human evaluative conditioning. Psychological Bulletin, 127, 853-869.

Dovidio, J.F., \& Fazio, R.H. (1992). New technologies for the direct and indirect assessment of attitudes. In J. Turner (Ed.), Questions about survey questions: Meaning, memory, attitudes, and social Interaction (pp. 204-237). New York: Russell Sage Foundation, 204237.

Fazio, R.H. (1990). A practical guide to the use of response latency in social psychological research. In C. Hendrick, \& M. S. Clark (Eds.), Research methods in personality and social psychology (pp. 74-97). California: Sage Publications, Inc.

Fazio, R.H., \& Olson, M.A. (2003). Implicit measures in social cognition research: Their meaning and use. Annual Review of Psychology, 54, 297-327. 
Fazio, R. H., Sanbonmatsu, D. M., Powell, M. C., \& Kardes, F. R. (1986). On the automatic activation of attitudes. Journal of Personality and Social Psychology, 50, 229238.

Fournier, S. (1998). Consumers and their brands: Developing relationship theory in consumer research. Journal of Consumer Research, 24, 343-373.

Geuens, M., \& De Pelsmacker, P. (2002). The moderating role of need for cognition on responses to humorous appeals. In S. M. Broniarczyck, \& K. Nakamoto (Eds.), Advances in Consumer Research (Vol. 29, pp. 50-56). Valdosta, GA: Association for Consumer Research.

Giner-Sorolla, R., Garcia, M. T., \& Bargh, J.A. (1999). The automatic evaluation of pictures. Social Cognition, 17, 76-96.

Govan, C. L., \& Williams, K. D. (2004). Stimulus items can influence the IAT effect: Reconstruing the category labels. Journal of Experimental Social Psychology, 40, 357365.

Greenwald, A. G., \& Banaji, M. R. (1995). Implicit social cognition: Attitudes, selfesteem, and stereotypes. Psychological Review, 102, 4-27.

Greenwald, A. G., McGhee D., \& Schwartz, J.L.K. (1998). Measuring individual differences in implicit cognition: the Implicit Association Test. Journal of Personality and Social Psychology, 74, 1464-1480.

Greenwald, A.G., \& Nosek, B. A. (2001). Health of the Implicit Association Test at age 3. Zeitschrift für Experimentelle Psychologie, 48, 85-93.

Grunert, S. C. (1993). Everybody seems concerned about the environment: But is this concern reflected in [Danish] consumers' food choice? In W. F. van Raaij, \& G. J. Bamossy (Eds.), European Advances in Consumer Research: Proceedings of the 1993 Conference (Vol. 1, pp. 428-433). Provo UT: Association for Consumer Research. 
Hermans, D., De Houwer J., \& Eelen P. (1994). The affective priming effect: Automatic activation of evaluative information in memory. Cognition and Emotion, 8, 515-533.

Inquisit 1.33 [Computer software] (2002). Seattle, WA: Millisecond Software.

Janiszewski, C. (1990). The influence of print advertisement organization on affect toward a brand name. Journal of Consumer Research, 17, 53-65.

Janiszewski, C., \& Meyvis, T. (2001). Effects of brand logo complexity, repetition, and spacing on processing fluency and judgment. Journal of Consumer Research, 28, 18-32.

Kardes, F. R., Allen, C.T., \& Pontes, M. J. (1993). Effects of multiple measurement operations on consumer judgment- measurement reliability or reactivity. In L. McAlister, \& M. L. Rothschild (Eds.), Advances in Consumer Research (Vol. 20, pp. 280-283). Provo, UT: Association for Consumer Research.

Lang, P. J., Bradley, M. M., \& Cuthbert, B. N. (1999). International Affective Picture System (IAPS): Instruction manual and affective rating. Technical report A-4, The Center for Research in Psychophysiology, University of Florida, Gainesville, FL 32611.

La Trobe, H. L., \& Acott, T.G. (2000). A modified NEP/DSP environmenal attitudes scale. Journal of Environmental Education, 32, 12-21.

Lowery, B.S., Hardin, C.D., \& Sinclair, S. (2001). Social influence effects on automatic racial prejudice. Journal of Personality and Social Psychology, 81, 842-855.

Maison, D., Greenwald, A.G., \& Bruin, R. (2001). The Implicit Association Test as a measure of implicit consumer attitudes. Polish Psychological Bulletin, 32, 61-70.

Maison, D., Greenwald, A.G., \& Bruin, R. (2004). Validity of the Implicit Association Test in studies of brands and consumer attitudes and behavior. Journal of Consumer Psychology, $14,405-416$.

McAlexander, J.H., Schouten, J.W., \& Koenig, H.F. (2002). Building brand community. Journal of Marketing, 66, 38-54. 
Mcfarland, S. G., \& Crouch, Z. (2002). A cognitive skill confound on the Implicit Association Test. Social Cognition, 20, 483-510.

Nosek, B. A., \& Banaji, M. R. (2001). The Go/ No-Go Association Task. Social Cognition, 19, 625-666.

Nosek, B.A., Banaji, M.R., \& Greenwald, A.G. (2002). Harvesting implicit group attitudes and beliefs from a demonstration website. Group Dynamics, 6, 101-115.

Nosek, B. A., Greenwald, A. G., \& Banaji, M. R. (2003). Understanding and using the Implicit Association Test: II. Methodological issues. Personality and Social Psychology Bulletin, 85, 197-216.

Patzer, G. L. (1985). The physical attractiveness phenomena. New York: Plenum Press.

Petty, R. E., \& Cacioppo, J. T. (1986). The elaboration likelihood model of persuasion. In Leonard Berkowitz Orlando (Ed.), Advances in Experimental Social Psychology (Vol. 19, pp. 123-205). FL: Academic Press.

Pham, M. T. (1998). Representativeness, relevance, and the use of feelings in decision making. Journal of Consumer Research, 25, 144-160.

Pham, M. T., Cohen, J. B., Prajecus, J. W., \& Hughes, D.G. (2001). Affect monitoring and the primacy of feelings in judgment. Journal of Consumer Research, 28, 167-188.

Roberts, J.A. (1996). Will the real socially responsible consumer please step forward?, Business Horizons, 39, 79-83.

Roozen, I.T.M. (1999). Milieu en consument, determinanten van milieuvriendelijk gedrag van consumenten (environment and consumer, determinants of environmentally friendly consumer behavior). Unpublished dissertation, Marketing Department, University of Antwerp: Antwerp, Belgium.

Roozen, I.T.M., \& De Pelsmacker, P. (1998). Attributes of environmentally friendly consumer behavior. Journal of International Consumer Marketing, 10, 21-41. 
Rudman, L. A., Greenwald, A. G., \& McGhee, D. E. (2001). Implicit self-concept and evaluative implicit gender stereotypes: self and in-group share desirable traits. Personality and Social Psychology Bulletin, 27, 1164-1178.

Rudman, L. A., \& Heppen, J. B. (2003). Sources of implicit attitudes toward smoking. Unpublished manuscript, Department of Psychology, Tillett Hall, Rutgers University, Piscataway, NJ 08854.

Schwepker, C. H., \& Cornwell, B. T. (1991). An examination of ecologically concerned consumers and their intention to purchase ecologically packaged products. Journal of Public Policy and Marketing, 10, 77-101.

Shapiro, S. (1999). When an ad's influence is beyond our conscious control: perceptual and conceptual fluency effects caused by incidental ad exposure. Journal of Consumer Research, 26, 16-36.

Shiv, B., \& Fedorikhin, A. (1999). Heart and mind in conflict: The interplay of affect and cognition in consumer decision making. Journal of Consumer Research, 26, 278-292.

Swanson, J. E., Rudman, L. A., \& Greenwald, A.G. (2001). Using the Implicit Association Test to investigate attitude-behavior consistence for stigmatized behavior. Cognition and Emotion, 15, 207-230.

Tallontire, A., Rentsendorj, E., \& Blowfield, M. (2001). Ethical consumers and ethical trade: A review of current literature. Policy Series 12, Natural Resources Institute.

Wänke, M., Plessner, H., \& Friese, M. (2002). When implicit attitudes predict brandchoice and when they don't. In R. Zwick, \& T. Ping (Eds.), Asia Pacific Advances in Consumer Research (Vol. 5, pp. 207-208). Valdosta, GA, Association for Consumer Research.

Wilson, T. D., Lindsey, S., \& Schooler, T. Y. (2000). A model of dual attitudes. Psychological Review, 107, 101-126. 
Wittenbrink, B., Judd, C.M., \& Park, B. (2001). Spontaneous prejudice in context: Variability in automatically activated attitudes. Journal of Personality and Social Psychology, 81, 815-827.

Yam-Tang, E. P.Y., \& Chan, R.Y.K. (1998). Purchasing behaviors and perceptions of environmentally harmful products. Marketing Intelligence and Planning, 16, 356-362. 
TABLE 1

Explicit and implicit attitudes toward the fictitious products as a function of purchase intention for real products in Experiment 1

\begin{tabular}{lcccc}
\hline \hline \multicolumn{5}{c}{ Product choice (between four real well-known brands of all purpose cleaners) } \\
\hline Attitude measure & $\begin{array}{c}\text { Green all-purpose } \\
\text { cleaner }\end{array}$ & $\begin{array}{c}\text { Traditional all- } \\
\text { purpose cleaner }\end{array}$ & $p$ & $t(60)$ \\
& $(n=12)$ & $(n=48)$ & & \\
\hline Explicit difference measure & .63 & .06 & .27 & 1.12 \\
IAT-effect (ms) & 132 & 29 & .05 & 1.99 \\
\hline
\end{tabular}


TABLE 2

\section{Explicit and implicit attitudes toward the fictitious products as a function of purchase intention for fictitious products in Experiment 1}

\begin{tabular}{lcccc}
\hline \hline \multicolumn{5}{c}{ Product choice (between the fictitious brands MATU and GIKO*) } \\
\hline Attitude measure & Green cleaning & Traditional & $p$ & $t(60)$ \\
& product & cleaning product & & \\
& $(n=40)$ & $(n=20)$ & & \\
\hline Explicit difference measure & .85 & -1.48 & $<.001$ & -5.48 \\
IAT-effect (ms) & 75 & 1.88 & .14 & -1.51 \\
\hline
\end{tabular}

* For half of the respondents MATU represented an environmentally-friendly cleaning product and GIKO a traditional cleaning product. For the other respondents MATU referred to a traditional cleaning product and GIKO to an environmentally-friendly cleaning product. 
TABLE 3

Explicit and implicit attitudes toward the assortments as a function of purchase intention for real products in Experiment 2

\begin{tabular}{lcccc}
\hline \hline \multicolumn{5}{c}{ Product choice (between four real well-known brands of all purpose cleaners) } \\
\hline Attitude measure & Green all-purpose & Traditional all- & $p$ & $t(67)$ \\
& cleaner & purpose cleaner & & \\
& $(n=29)$ & $(n=38)$ & & \\
\hline Explicit difference measure & .74 & -.75 & $<.001$ & 4.09 \\
IAT-effect (ms) & 62 & -30 & .04 & 2.04 \\
\hline
\end{tabular}


TABLE 4

Explicit and implicit attitudes toward the assortments as a function of behavioral intention for the assortments in Experiment 2

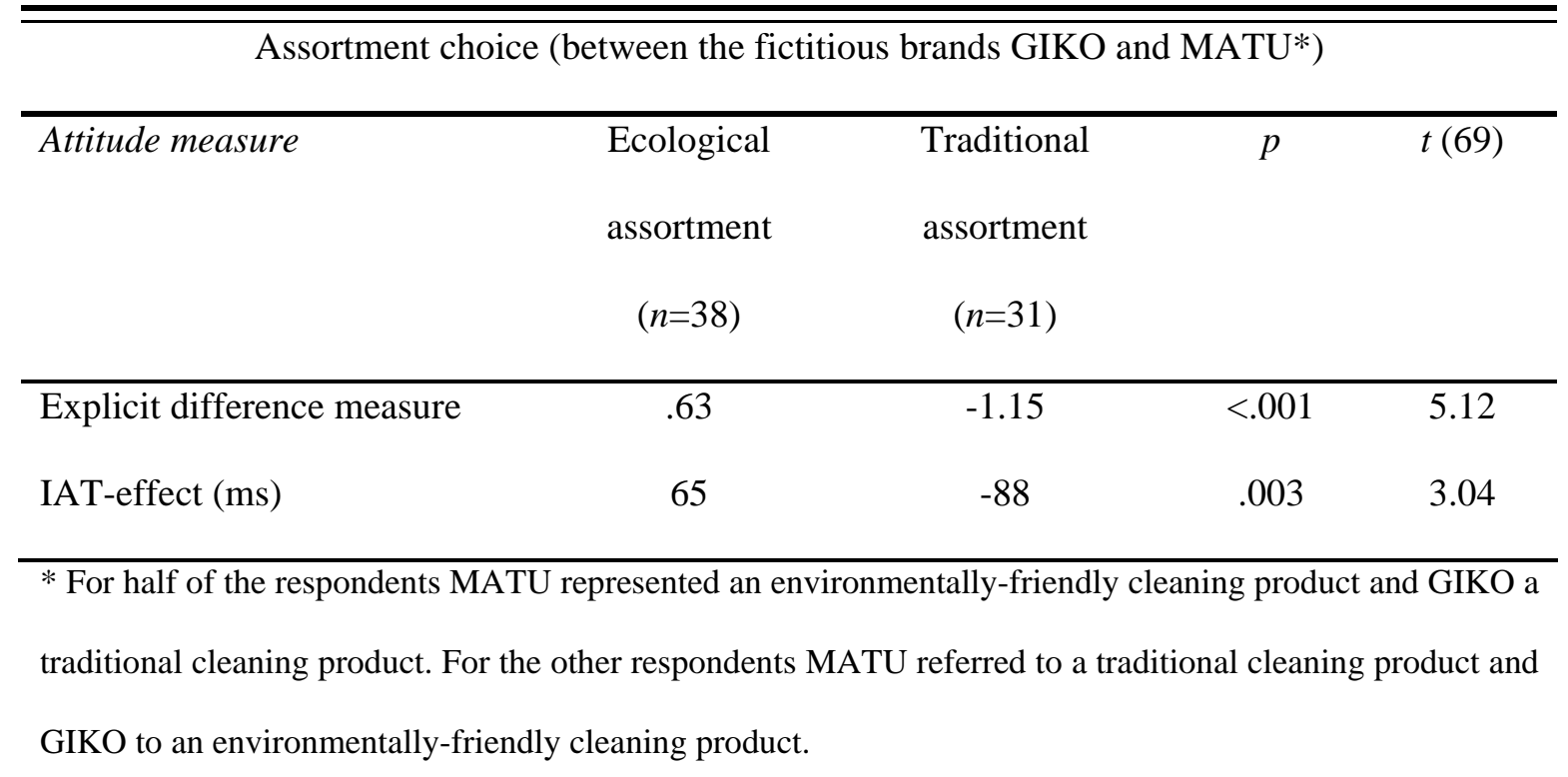

